\title{
Wave modeling and extreme value analysis off the northern coast of the Persian Gulf
}

\author{
M. H. Moeini ${ }^{\text {a }}$, A. Etemad-Shahidi ${ }^{\text {a**, }}{ }^{\text {V. Chegini }}{ }^{\text {b }}$ \\ ${ }^{a}$ School of Civil Engineering, Iran University of Science and Technology, Tehran, Iran, \\ P.O. Box 16765-163, Tel.: +9821 77240399, Fax: +9821 77454053. \\ ${ }^{\mathrm{b}}$ Iranian National Center for Oceanography, Tehran, Iran. \\ *E-mail: mhmoeini@iust.ac.ir \\ ** Corresponding Author, E-mail: etemad@iust.ac.ir
}

\begin{abstract}
This study aims to assess the quality of two sources of surface winds, i.e. the ECMWF (European Center for Medium Range Weather Forecasts) and measured data, for wave modeling in the Persian Gulf. The third generation SWAN model was employed for wave simulation and the results were compared with recorded wave data. It was found that ECMWF underestimates the wind magnitude and the results of the wave modeling need to be modified. In addition, it was revealed that adaptation of model parameters can not lead to comprehensive improvement of model's results. Calibration of the wave model for high waves led to overestimation of low waves. On the other hand, the employed measured wind data was found to be a relatively good source for wave hindcasting at the studied location. Extreme value analysis was conducted based on the measured and modeled wave data to investigate the influence of wave simulation on the estimation of design wave height. It was found that the Weibull distribution is better fitted to the measured and modeled wave data. Modeled wave heights forced by ECMWF wind showed different behavior compared with measured and modeled wave heights forced by measured wind from the viewpoint of exceedance probability.
\end{abstract}


Marginal difference was found between extreme wave heights obtained from measured and modeled data.

Keywords: Wind waves; Wave modeling; Wind fields; Persian Gulf; SWAN; Extreme waves

\section{Introduction}

The economical design of marine structures requires accurate estimation of long term data about environmental conditions such as waves. The design of coastal and offshore structures is based on design significant wave height corresponding to a certain return period. The design wave height is obtained by collecting short-term, e.g. 3-hourly, data at the given location. Instrumentally measured, visually observed or numerically simulated wave data can be used for this purpose [1]. Ocean and coastal engineers generally use these data associated with statistical methods to determine wave climate at a desired probability.

Due to the lack of measurements and observations in many regions, and development of numerical wave models, nowadays numerically simulated wave data are widely used as the data bank for extracting design wave characteristics. Since there are many sources for wind forcing in numerical wave models, selection of the most appropriate source and investigation of the effect of different wind sources on both wave modeling and calculation of extreme waves is very important.

\section{Previous works}

Many researchers have studied the quality of modeled surface winds for wave modeling. Signell et al. [2] assessed the quality of four sources of wind fields including ECMWF for use in wave modeling at the Adriatic Sea. They used the SWAN model for 
wave simulation and found that ECMWF global model T511 (with nearly $40 \mathrm{~km}$ spatial resolution) underestimates the wind speed by $36 \%$. They also showed that ECMWF wind data are very smooth and do not reproduce the spatial structure of strong wind events. Based on their findings, the modeled wave heights had an average underestimation of more than 50\% compared with recorded wave height in three stations. Cavaleri and Scalvo [3] evaluated the quality of ECMWF T511 wind fields in the Mediterranean Sea. They illustrated that ECMWF wind data, in contrast to measured data, are substantially underestimated. In their study the modeled wave height were also underestimated mainly due to underestimation of driving wind fields. Brenner at al. [4] simulated wind waves in the Mediterranean Sea using WAM model forced by several sources of modeled surface winds including ECMWF ERA-1 $\left(0.5^{0}\right.$ spatial resolution). Based on their results, ECMWF wind data had a bias value of $0.3 \mathrm{~m}$ against measurements with a scatter index of 0.43 . They showed that WAM model forced by ECMWF underestimates the significant wave height mostly due to low resolution and underestimation of ECMWF wind forcing. Caires and Sterl [5], Cavaleri and Bertotti [6] and Ardhuin et al. [7] also reported the underestimation of ECMWF wind fields in different cases.

Caires and Sterl [8] estimated global return value for significant wave height based on the ERA-40 data set. ERA-40 is the name of most recent reanalysis of global meteorological parameters in ECMWF, including ocean winds and waves, from 1957 to 2002. The wind and wave data used in their study consisted of 6-hourly fields on a $1.5^{\circ}$ $\times 1.5^{\circ}$ latitude/longitude grid covering the whole globe. They found that the ERA-40 data underestimates the high values of $H_{s}$. Therefore, they proposed a linear relationship to correct estimated return values based on the buoys return value estimates. 
Despite the fact that Caires and Sterl [8] have estimated extreme wave height for the total oceans of the earth, their results can not provide comprehensive information about countries surrounding the Persian Gulf mainly due to the lack of field data and resolution. They validated and corrected their findings based on wave measurements around the continent of America. Therefore, their results for the Persian Gulf have not been validated. In addition, they estimated the return values based on information on a $1.5^{\circ} \times 1.5^{\circ}$ grid. Since the width of the Persian Gulf is of the order of $1.5^{\circ}$ only, their used grid can not provide detailed information for the countries around the Persian Gulf. Neelamani et al. [9] estimated design wave characteristics for Kuwaiti territorial waters based on 12-year simulated data with WAM model on a $0.1^{\circ} \times 0.1^{\circ}$ grid and $0.5^{\circ} \times 0.5^{\circ}$ ECMWF wind forcing. They used Peaks over Threshold method to extract storm data and employed Weibull and Gumbel distribution to estimate extreme wave characteristics. According to their findings, the Weibull distribution is better fitted to the storms compared with Gumbel distribution in Kuwaiti territorial waters. They validated their results against the measurements in Kuwaiti waters and the validity of their findings along Iranian coasts needs to be proved. In addition, they did not discussed the effect of modeling results on the extreme value analysis of wave data and the quality of ECMWF wind source for wave hindcasting in the Persian Gulf.

The main goal of this study is to assess the quality of two sets of wind data for using in numerical wind wave model and investigate the use of numerically simulated wave data as a data base for extreme wave analysis at the Northern coast of the Persian Gulf. The third generation SWAN model [10] is used for wave hindcasting and reproducing time series of wave data. Both measured and ECMWF wind data are evaluated as the wind input in the SWAN model. The model results are compared with field measurement both from the viewpoints of wave hindcasting and extreme value analysis. Some 
remarks on extreme wave estimation in this region such as the appropriate distribution and effect of threshold value are also presented.

This paper is organized as follows. Section 2 introduces the study area and the field data. Section 3 gives a brief description of the SWAN numerical model, and the results and discussions are described in section 4. Finally, section 5 covers the summary and conclusions.

\section{Study area and field data}

The Persian Gulf is a marginal sea in a typical dry zone and is an extension of the Indian Ocean. It is located between the longitude of $48-57^{\circ} \mathrm{E}$ and the latitude of $24-30^{\circ} \mathrm{N}$ (Fig. 1). This inland sea is connected to the Gulf of Oman in the East by the Strait of Hormuz. The gulf includes an area of $226000 \mathrm{~km}^{2}$. It is $990 \mathrm{~km}$ long and its width varies from 56 to $338 \mathrm{~km}$, separating Iran from Arabian Peninsula with the shortest distance of about $56 \mathrm{~km}$ in the Strait of Hormuz. This Gulf has an average depth of about $35.0 \mathrm{~m}$ and the deepest water depth is about $107 \mathrm{~m}[11,12]$.

Assaluyeh area in Iran located at $52^{\circ} 36^{\prime} E$ and $27^{\circ} 30^{\prime} N$ is the closest land point to the largest natural gas field in the world, the South Pars/North Dome Gas-Condensate field. There are many coastal and offshore industrial projects under construction or planning in this area. Therefore, accurate prediction of wave climate is vital in this area. The recorded wave data used in this study were collected by an AWAC buoy which was located in $52^{\circ} 30^{\prime} 17^{\prime \prime} E$ and $27^{\circ} 35^{\prime} 39^{\prime \prime} N$. The data were recorded hourly from the first of November, 2002 until $31^{\text {st }}$ October, 2003. Fig. 1 illustrates the location of wave measurement station.

Since the quality of wind data as the most important input greatly affects the accuracy of the results, the selection of appropriate wind forcing is an essential prerequisite for 
obtaining reliable wave hindcasting. Therefore, two sources of wind data, i.e. the measured and ECMWF wind data, were used and evaluated for wind input in the SWAN model. The wind measurement station called Dayyer station was located in $51^{0} 56^{\prime} E$ and $27^{\circ} 50^{\prime} N$, which was the nearest station to the wave recording location. This meteorological station is located on a flat plain with a distance of about $100 \mathrm{~m}$ from the shoreline. The nearest mountain range to this station is about $20 \mathrm{~km}$ away. The wind data in this station have been recorded 3-hourly from the beginning of 1993. The elevation of the anemometer is $4 \mathrm{~m}$ over the ground level. Since the wave model uses wind velocity at 10-meter elevation, the following equation was used to modify the velocities [13]:

$$
U_{10}=U_{Z}\left(\frac{10}{z}\right)^{\frac{1}{7}}
$$

The second source of wind data was the 6-hourly $10 \mathrm{~m}$ operational ECMWF wind data with a resolution of $0.5^{\circ}$. It should be noted that ECMWF operational was selected because of its higher spatial resolution than ECMWF re-analysis $\left(1.125^{\circ}\right.$ spatial resolution).

\section{The SWAN model}

The SWAN model $[10,14]$ is a third generation spectral wind wave model, designed to obtain reliable estimates of wave parameters in coastal areas. Since in the presence of currents energy density is not conserved, action density spectrum is considered in the SWAN model rather than energy density spectrum. The action density is equal to the energy density divided by the relative frequency:

$$
N(\sigma, \theta)=E(\sigma, \theta) / \sigma
$$


The independent variables are the relative frequency $\sigma$ (as observed in a frame of reference moving with current velocity) and the wave direction $\theta$ (the direction normal to the wave crest of each spectral component). In the SWAN wave model the evolution of the wave spectrum in the position $(x, y)$ and time $(t)$ is described by the spectral action balance equation which for Cartesian coordinates is [10]:

$$
\frac{\partial}{\partial t} N+\frac{\partial}{\partial x} C_{x} N+\frac{\partial}{\partial y} C_{y} N+\frac{\partial}{\partial \sigma} C_{\sigma} N+\frac{\partial}{\partial \theta} C_{\theta} N=\frac{S}{\sigma}
$$

The first term in the left-hand side of this equation represents the local rate of change of action density in time, the second and third terms represent propagation of action in geographical space with propagation velocities $C_{x}$ and $C_{y}$ in $x$ and $y$ space, respectively. The fourth term represents shifting of the relative frequency due to variations in depths and currents (with propagation velocity $C_{\sigma}$ in $\sigma$ space). The fifth term represents depth-induced and current-induced refraction and propagation in directional space (with propagation velocity $C_{\theta}$ in $\theta$ space; [10]).

The term $S=S(\sigma, \theta)$ at the right hand side of the action balance equation is the source term in terms of energy density representing the effects of generation, dissipation and nonlinear wave-wave interactions. This term consists of linear and exponential growth by wind, dissipation due to whitecapping, bottom friction and depth-induced wave breaking and energy transfer due to quadruplet and triad wave-wave interaction. In this study SWAN cycle III version 40.41 [15] was used for wave simulation.

\section{Results and discussion}

\subsection{Wave modeling}

In the current study the SWAN model was executed in third generation and nonstationary mode with Cartesian coordinates. Since it has been revealed that using 
Komen's formulation [16] for wind input parameterization leads to more accurate prediction of $H_{s}$ [17], this expression was used for exponential growths of wind input. Quadruplet wave interaction was activated for nonlinear interaction as well. Dissipation due to whitecapping, bottom friction and depth-induced wave breaking were considered in the simulation.

The geographical domain was discretized into $125 \times 100$ cell grid covering the Persian Gulf with $8800 \times 8000$ meter resolution in $x$ and $y$ directions, respectively. The spectral space was divided into 25 equal directions in the rose $\left(\Delta \theta=360^{\circ} / 25=14.4^{0}\right)$ and 25 logarithmically spaced frequencies, between $0.06 \mathrm{~Hz}$ and $1 \mathrm{~Hz}$. This means that the lowest period of simulated wave was 1 second and the highest was approximately 17 seconds covering typical surface waves in the Persian Gulf. The computational time step was selected as 10 minutes as well.

The first used wind source was Dayyer measurements which were inputted into the model as a spatially-constant wind input. As mentioned before, the wind data at the nearest station to the wave measurement location was taken for this purpose. The second wind force was the ECMWF wind data varying in time and domain. Both of these sources had their own advantages and disadvantages. The former data was measured directly and had a finer temporal resolution (3 hours), but in this wind input source the spatial variation of wind features over the geographical domain was ignored. The latter wind source was the results of atmospheric model and had a coarser temporal resolution (6 hours), but the spatial variation of wind characteristics was considered in it. The SWAN model was executed with these input sources and the difference and suitability of these sources from the viewpoint of wave modeling was analyzed based on the outputs of the SWAN model. 
The calibration of the model was conducted based on the recorded wave data during November, 2002. The tunable parameter used for calibration was the rate of whitecapping dissipation. Sensitivity analysis showed that other physical parameters such as depth induced wave breaking and bottom friction have no significant effect on the wave characteristics. Fig. 2 illustrates simulated significant wave height with default (non-calibrated) and calibrated parameter forced by Dayyer and ECMWF wind data. As seen in Fig. 2, using non-calibrated model forced by Dayyer wind data has led to slight overestimation of wave height. In addition, simulation of wind waves with noncalibrated model forced by ECMWF wind data has resulted in considerable underestimation of high waves. This can be due to underestimation of wind speed by ECMWF. To investigate this subject, statistical specifications of Dayyer recorded and ECMWF modeled wind speed for wave heights greater than 0.5 meter are shown in Table 1. As seen, the average of computed ECMWF wind speed in the calibration period is about 30 percent lower than that of recorded wind speed in Dayyer station. In addition, the maximum and standard deviation of ECMWF wind speed are considerably lower than those of measurements indicating underestimation of ECMWF wind data. Similar results were found for the verification period which will be discussed later. These results reveal the importance and necessity of calibration process or updating of wave model's result based on observed data in this condition. Generally these findings are in agreement with those of Signell et al. [2], Brenner at al. [4], Caires and Sterl [5], Cavaleri and Bertotti [6], Ardhuin et al. [7] and Janssen et al. [18] showing underestimation of ECMWF wind data.

After calibration, a two-month recorded wave data during December, 2002 and January, 2003, was selected to verify the results of calibration process. Fig. 3 and 4 give qualitative comparisons of the hourly time series of modeled significant wave height 
forced by measured and ECMWF winds against the measurements in the verification period, respectively. As seen, simulations with two source terms follow the measurements quite well. However, there are a few inconsistencies or delays between measurement and modeled data in both Dayyer and ECMWF wind forcing. This could be due to the difference between actual and modeled wind in case of ECMWF, caused by atmospheric modeling and orography effects. In case of Dayyer forcing, using spatially-constant wind speed and ignoring the wind speed variability may result in the observed inconsistencies. In addition, there are more fluctuations in the modeled wave height forced by measured wind speed as opposed to that forced by ECMWF wind speed. In other words, the model's results forced by ECMWF are smoother than those forced by Dayyer wind data. This could be due to two reasons. Firstly, the Dayyer wind data had finer temporal resolution (3 hours) compared with ECMWF wind data (6 hours). Thus, it is possible that some peaks with durations less than 6 hours were ignored in ECMWF data. Secondly, as mentioned before, the ECMWF data are the outputs of an atmospheric model and sometimes these models can not reproduce the peaks very well and tend to smooth their results [2]. The wind roses of Dayyer and ECMWF for this period are illustrated in Fig. 5. As seen, ECMWF wind rose is generally consistent with Dayyer wind rose from the viewpoint of prevailing direction. High speed winds in ECMWF wind rose are less observed compared with those of Dayyer wind rose as discussed before.

In addition to above issues, it can be seen in Fig. 4 that in the case of ECMWF forced results, the simulated wave heights for high values are closer to the measurements compared with the simulated low wave heights. The modeled wave heights for small values are higher than the corresponding measurements. To explain this, it should be noticed that the goal of wave height hindcasting in this study was to investigate the 
effect of modeling on the extreme wave analysis. Therefore, since the low wave heights are omitted in extreme wave analysis (by the Peaks over Threshold method) the focus of calibration was on the simulation of high waves. Thus, since the ECMWF wind data were underestimated (Table 1), the calibration of high values has led to overestimation of low wave heights.

After calibration and verification of the SWAN model, one year wave hindcasting was implemented during the measurement period. For the total hindcast period mentioned above, distribution of measured significant wave height against those simulated by SWAN model with measured and ECMWF winds are represented in Tables 2 and 3, respectively. In these tables, numbers are records within each category (in percent of total) and in the case of perfect model performance, only the diagonal elements would be filled. The results are classified into $0.5 \mathrm{~m}$ intervals and the maximum probability for each category is shown in bold type.

Comparison of these two tables shows that the Dayyer forced simulated data demonstrate smaller dispersion for low wave heights rather than ECMWF forced data. In contrast to low wave heights, the dispersion of ECMWF forced hindcasted data is smaller for high wave heights rather than that of Dayyer forced simulated data. This is due to underestimation of wind speed by the ECMWF which results in overestimation of low wave heights in calibration process. These results show that adaptation of model parameters for improving of outputs does not necessarily lead to comprehensive improvement of model's results. Therefore, it is recommended that for more accurate prediction of all ranges of wave data, some other exhaustive methodologies such as updating of output variables (error prediction) be employed [19]. However, the maximum probability for each category of the measured wave height is located at its 
corresponding category from modeled data. This means that calibration process has been led to relatively correct estimation of significant wave height intervals.

Alari et al. [20] used spatially-uniform wind data for wave simulation. It should be noted that using spatially-uniform wind input has some limitations for wind wave simulation. However, in the studied area accurate high-resolution wind fields, which are generally outputs of local meteorological models, were not available. In the current study which aimed to wave modeling in one station, using spatially-constant wind input has led to better results compared with using ECMWF data. In order to evaluate wind wave simulation over the Persian Gulf, it is planned to use ECMWF wind source associated with assimilation methods.

\subsection{Extreme wave analysis}

After hindcasting one year wave data, extreme value analysis was conducted based on the measured and modeled wave data. The objective of this section was to compare the results of wave hindcasting in the studied area from the viewpoint of extreme wave analysis.

Generally, there are three different approaches for preparing the sample of wave data to be used for extreme value analysis. In the first approach the whole data of wave heights during a number of years is employed and distribution functions are fitted to cumulative distribution of these data. This method is called the total sample method, initial distribution method or the cumulative distribution function method. In the other two approaches only the peaks of wave heights are employed. The annual maxima method collects the highest significant wave height in each year, whereas in the Peaks over Threshold (POT) method the peak heights occurring during each storm over a certain threshold value are taken. Since the prerequisite of statistical independence is not 
satisfied in the total sample method, and the annual maxima method provides short record of extreme data, the POT method is recommended for extraction of the storms for extreme value analysis $[1,21]$. In the present study this method was used with a primary threshold wave height value of $0.5 \mathrm{~m}$. The number of extreme wave events were 120, 138 and 87 for measured, Dayyer and ECMWF wind forced simulated waves, respectively. The probability of exceedance of wave heights was calculated using grouped data rather than ordered data and plotting position formulas [21]. In this method, the extreme events are classified into wave height intervals and the exceedance probability is defined based on the number of events recorded in each interval and the total number of extreme data. More details can be find in [21].

The Log-Normal, Gumbel and Weibull distributions were employed for extreme value prediction. The correlation coefficients between reduced variates of these distributions and significant wave height are presented in Table 4 for modeled and measured data. It can be seen that the Weibull distribution is better fitted to the measured and both sources of modeled storms compared to the other three distributions. This can be due to the fact that Weibull distribution is a 3-parameter distribution while the other three distributions are 2-parameter distributions. Therefore, the fitting of weibull distribution to the data can be better done. This distribution was used for further investigations in this study. Neelamani et al. [9] also found that Weibull distribution is better for Kuwaiti territorial waters in the Persian Gulf.

Fig. 6 illustrates the reduced variates of Log-Normal, Gumbel and Weibull distributions versus significant wave height $\left(\ln \left(H_{S}\right)\right.$ in the case of $\log$-Normal distribution) for measured and modeled data. The linear best fit to this data is also shown on these figures. As seen, although there are higher wave heights in modeled data using Dayyer wind compared with measured data, this two sources of data are consistent in reduced 
variate and their fitted lines are nearly the same. It can be seen that modeled data with ECMWF wind shows different behavior compared with other two sources from the viewpoint of probability of exceedance of wave height. In addition, the parameter values for the fitted Weibull distribution for the measured and simulated waves forced by Dayyer and ECMWF wind are presented in Table 5. As seen, the fitted Weibull distribution parameters for the modeled waves forced by Dayyer wind are closer to those of measured data rather than modeled data forced by ECMWF wind. This issue also shows the different behavior of simulated waves forced by ECMWF wind compared with waves obtained by other two sources of data.

In order to evaluate the results quantitatively, the return values of significant wave height were estimated based on three sources of wave data. Table 6 shows the extreme wave heights with different return periods for measured and simulated data predicted by the Weibull distribution.

As seen in Table 6, the errors of estimation of extreme wave heights are between 6 to 8 percent based on numerically simulated data forced by Dayyer wind for 2 to 50 year return periods. These errors are between 13 to 16 percent for modeled data forced by ECMWF wind. Therefore, it can be concluded that the numerically simulated wave data can be used as a suitable database for estimation of design wave heights with reasonable accuracy in this area. It should be noted that using modeled data has led to overestimation of design wave height in both cases. In addition, according to Table 6 , the error of estimation of extreme waves based on simulated data forced by ECMWF wind is approximately two times larger than that of simulated forced by Dayyer wind. This is due to more accurate hindcasting of wave heights with Dayyer wind data which was discussed before. In addition, it can be seen that the errors increase as the return period increases. This phenomenon shows the increase of confidence intervals for 
higher return periods. It should be pointed that the aim of this analysis was to evaluate the effect of wind forcing on the extreme wave prediction. Since the recorded data were available only for 1 year, extreme value analysis was conducted based on 1 year measured and modeled data for having a fair comparison. Although extreme wave heights may contain unreliability because of shortness of data, this issue affects all of wave data sources in the same way. In other words, the aim of this analysis was not to compute the value of extreme wave heights, but it was to asses the differences between extreme values derived from different data sources.

To inspect the influence of threshold value on the estimation of design wave height a threshold wave height of $1 \mathrm{~m}$ was selected and extreme value analysis was conducted again. In this case the number of extreme events were reduced to 57,75 and 63 for measured, Dayyer and ECMWF wind forced modeled waves, respectively. Table 7 presents the extreme wave heights estimated by the Weibull distribution with $1 \mathrm{~m}$ threshold. Comparison with Table 6 shows that increasing of the threshold value has led to reduction of estimated return values for all cases.

The difference between design wave heights obtained from two threshold values are higher for measured data compared with two sources of modeled data. This can be due to smoothing of wave height time series by the numerical model [2]. In addition, the error of extreme wave height estimation using modeled data increases as the threshold value increases. This may be due to the increase of confidence intervals as a result of reduction in the number of storms (associated with increasing of threshold value).

\section{Summary and conclusions}

In this study two sources of wind data for wind wave simulation at the northern coast of the Persian Gulf were assessed. The wind sources consisted of recorded data at the 
nearest meteorological station to the wave measurement location called Dayyer and ECMWF data. The third generation spectral SWAN model was used for wind wave simulation and the results were compared with recorded wave data both from the viewpoint of wave hindcasting and extreme value analysis. The goal of the extreme analysis was to asses the effect of wind forcing on the extreme wave prediction. It should be mentioned that the predicted extreme wave heights may contain unreliability because of the shortness of measured data. However, this issue affects three data sources in the same way and the results can be compared fairly with each other. The obtained results are summarized as follows:

- Using Dayyer station wind data as the wind input results in slight overestimation of wave height and there are some inconsistencies mostly due to ignoring of spatial wind speed variability. Measured data have higher temporal resolution compared with ECMWF data and more fluctuations are seen in hindcasted data forced by this source. Generally, Dayyer measured data can be used for wave hindcasting in this area with reasonable accuracy.

- Non-calibrated simulated data forced by ECMWF are considerably underestimated due to significant underestimation of wind speed by ECMWF. Simulated waves forced by ECMWF are more smoothed rather than those forced by measured winds mostly due to lower temporal resolution and atmospheric modeling effects on the estimation of peaks in wind speed time series.

- Since the ECMWF wind speeds are underestimated, the model's result should be updated based on the observed data. Improving of model's outputs using adaptation of model parameters leads to overestimation of low wave heights. This shows the necessity of employing more comprehensive methodologies such as error prediction for more accurate prediction of all ranges of wave data. 
- For extreme value analysis, the 3-parameter Weibull distribution is better fitted to the measured and two sets of modeled data. From the viewpoint of probability of exceedance of wave height, modeled data forced by ECMWF wind shows different behavior compared with others.

- Using numerically simulated data for extreme wave analysis results in overestimation of design wave height. The error of estimation of extreme wave height based on ECMWF forced simulated data is higher than that of forced by Dayyer recorded data. Generally, the amount of errors is negligible and numerically simulated data can be used as a data base for extreme wave analysis.

It is recommended that for more comprehensive evaluation of ECMWF data several recorded wind and wave sets be collected. In addition, comparison needs to be made between ECMWF wind speed and corresponding modeled waves and measured values in different locations. Discovering the error distribution of ECMWF winds over the domain is also a matter of interest. Using more comprehensive methodologies for updating of wave model's results such as error prediction and its distribution over the spatial domain is recommended. Finally, implementing the wind wave model for longer periods to reduce unreliability in extreme value analysis is suggested.

\section{Acknowledgments}

We acknowledge the Iranian National Center for Oceanography and Iranian Meteorological Office for allowing us to use their Data. Mr. Mostafa Nazarali is thanked for his constructive comments. We would also like to express our gratefulness to the SWAN group at Delft University of Technology (Department of Fluid Mechanics) for providing the model. This study was supported by the Deputy of Research, Iran University of Science and Technology. 


\section{References}

[1] Goda Y. Statistical analysis of extreme waves (Chapter 11). In: Random seas and design of maritime structures, $15^{\text {th }}$ volume of advanced series on ocean engineering, World Scientific Publishing Co., 2000; 377- 425.

[2] Signell R.P., Carniel S., Cavaleri L., Chiggiato J., Doyle J.D., Pullen J., Sclavo M. Assessment of wind quality for oceanographic modelling in semi-enclosed basins. Journal of Marine Systems 2005; 53: 217- 233.

[3] Cavaleri L., Sclavo M. The calibration of wind and wave model data in the Mediterranean Sea. Coastal Engineering 2006; 53: 613-627.

[4] Brenner S., Gertman I., Murashkovsky A. Preoperational ocean forecasting in the southeastern Mediterranean Sea: Implementation and evaluation of the models and selection of the atmospheric forcing. Journal of Marine Systems 2007; 65: $268-287$.

[5] Caires S., Sterl A. A New Nonparametric Method to Correct Model Data: Application to Significant Wave Height from the ERA-40 Re-Analysis. Journal of Atmospheric and Oceanic Technology 2005; 22(4): 443-459.

[6] Cavaleri L., Bertotti L. The improvement of modelled wind and wave fields with increasing resolution. Ocean Engineering 2006; 33: 553-565.

[7] Ardhuin F., Bertotti L., Bidlot J.R., Cavaleri L., Filipetto V., Lefevre J.M., Wittmann P. Comparison of wind and wave measurements and models in the Western Mediterranean Sea. Ocean Engineering 2007; 34: 526-541.

[8] Caires S., Sterl A. 100-Year return value estimates for ocean wind speed and significant wave height from the ERA-40 data. Journal of Climate 2005; 18 (7): 1032-1048. 
[9] Neelamani S., Al-Salem K., Rakha K. Extreme waves for Kuwaiti territorial waters. Ocean Engineering 2007; 34: 1496-1504.

[10] Booij N., Ris R.C., Holthuijsen L.H. A third generation wave model for coastal regions. 1. Model description and validation. Journal of Geophysical Research 1999; 104: 7649-7666.

[11] Emery K.O. Sediments and water of the Persian Gulf. Bulletin of the American Association of Petroleum Geologists 1956; 40 (10): 2354-2383.

[12] Purser B.H., Seibold E. The principal environmental factors influencing Holocene sedimentation and diagenesis in the Persian Gulf. In: Purser, B.H. (Ed.), Persian Gulf, Berlin, 1973; 1-9.

[13] U.S. Army. Shore Protection Manual. 4th ed., 2vols. U.S. Army Engineer Waterways Experiment Station, U.S. Government Printing Office, Washington, DC., 1984.

[14] Ris R.C., Holthuijsen L.H., Booij N. A third-generation wave model for coastal regions. 2. Verification. Journal of Geophysical Research 1999; 104: 7667-7681.

[15] Booij N., Haagsma IJ.G., Holthuijsen L.H., Kieftenburg A.T.M.M., Ris R.C., Van der Westhuysen A.J., Zijlema M. SWAN User Manual (Cycle III version 40.41). Delft University of Technology, Delft, 2004.

[16] Komen G.J., Hasselmann S., Hasselmann K. On the existence of a fully developed wind sea spectrum. Journal of Physical Oceanography 1984; 14: 1271-1285.

[17] Moeini M.H., Etemad-Shahidi A. Application of two numerical models for wave hindcasting in Lake Erie. Applied Ocean Research 2007; 29: 137-145. 
[18] Janssen P. A. E. M., Hansen B., Bidlot J.R. Verification of the ECMWF wave forecasting system against buoy and altimeter data. Weather and Forecasting 1997; 12(4): 763-784.

[19] Babovic V., Sannasiraj S.A., Chan E.S. Error correction of a predictive ocean wave model using local model approximation. Journal of Marine Systems 2005; 53: 117.

[20] Alari V., Raudsepp U., Kõuts T. Wind wave measurements and modelling in Küdema Bay, Estonian Archipelago Sea. Journal of Marine Systems 2008; 74: S30- S40.

[21] Kamphuis J.W. Long term wave analysis (Chapter 4). In: Introduction to Coastal Engineering and Management, $16^{\text {th }}$ volume of Advanced Series on Ocean Engineering, World Scientific Publishing Co., 2000; 81-102. 


\section{Figure's Caption:}

Fig. 1. The Persian Gulf and location of Dayyer meteorological wind and wave measurement station.

Fig. 2. Comparison of calibrated and non-calibrated modeled data against the measurements in calibration period (a) Dayyer wind forced data (b) ECMWF wind forced data.

Fig. 3. Time series of wind and wave data in verification period with Dayyer wind forcing (a) Dayyer wind speed (b) Dayyer wind direction (c) Qualitative comparison of SWAN simulated (solid line) and measured (dots) Significant wave height.

Fig. 4. Time series of wind and wave data in verification period with ECMWF wind forcing (a) ECMWF wind speed (b) ECMWF wind direction at the wave measurement location(c) Qualitative comparison of SWAN simulated (solid line) and measured (dots) Significant wave height.

Fig. 5. Dayyer (a) and ECMWF (b) wind roses in verification period.

Fig. 6. (a) Log-Normal (b) Gumbel and (c) Weibull distribution plots for measured and modeled data. 


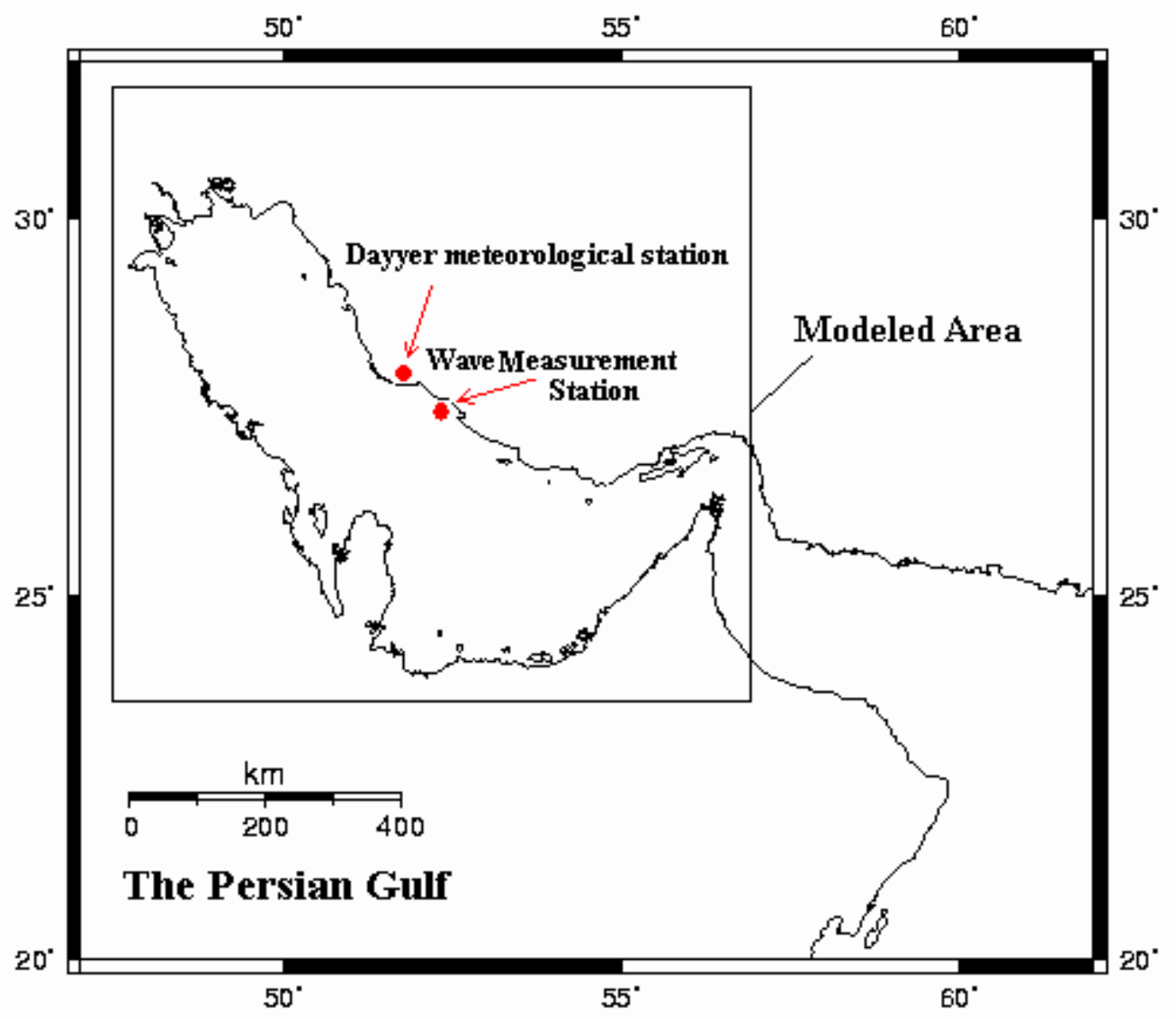

Fig. 1. The Persian Gulf and location of Dayyer meteorological wind and wave measurement station. 


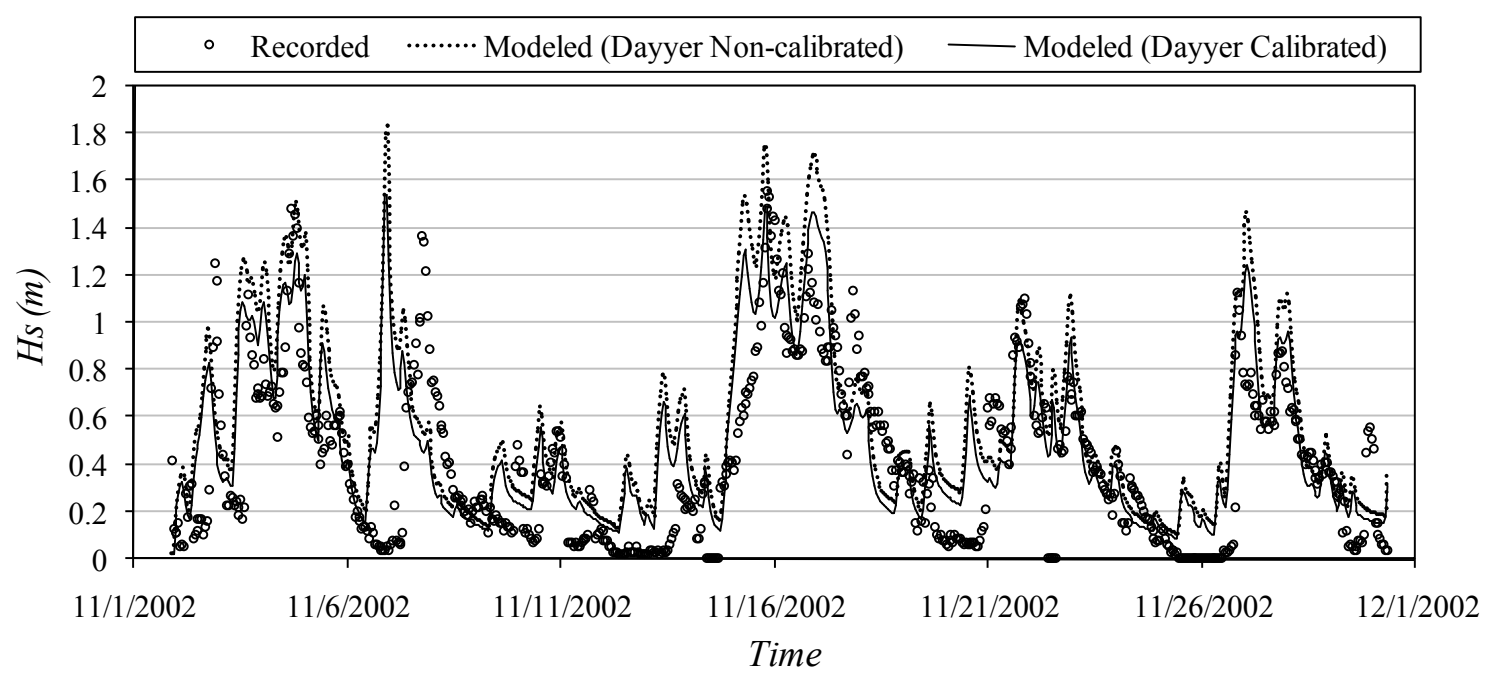

(b)

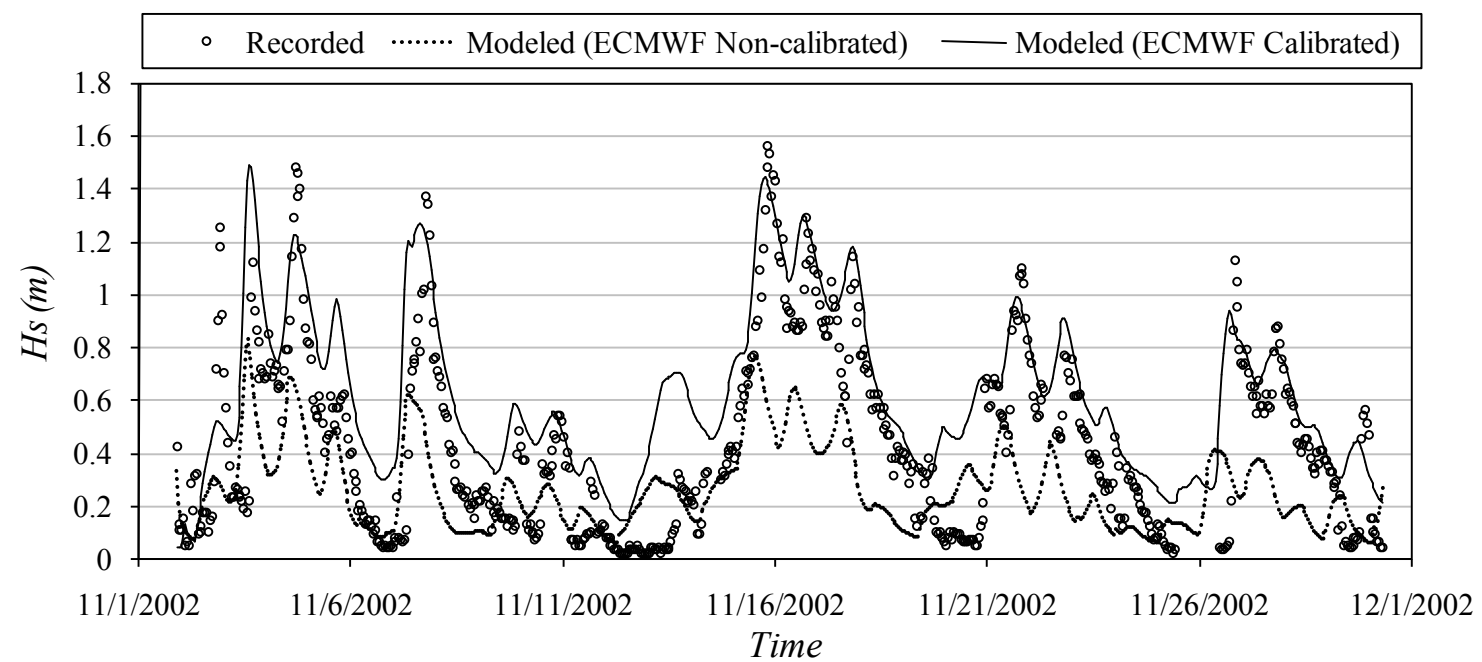

Fig. 2. Comparison of calibrated and non-calibrated modeled data against the measurements in calibration period (a) Dayyer wind forced data (b) ECMWF wind forced data. 
(a)

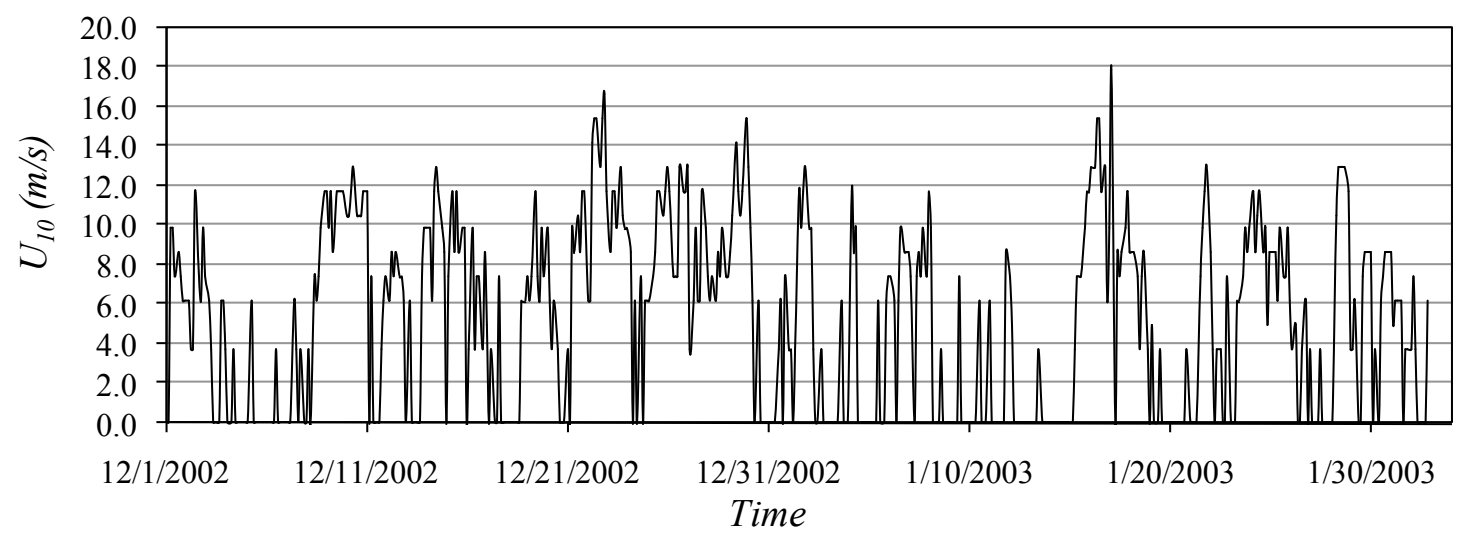

(b)

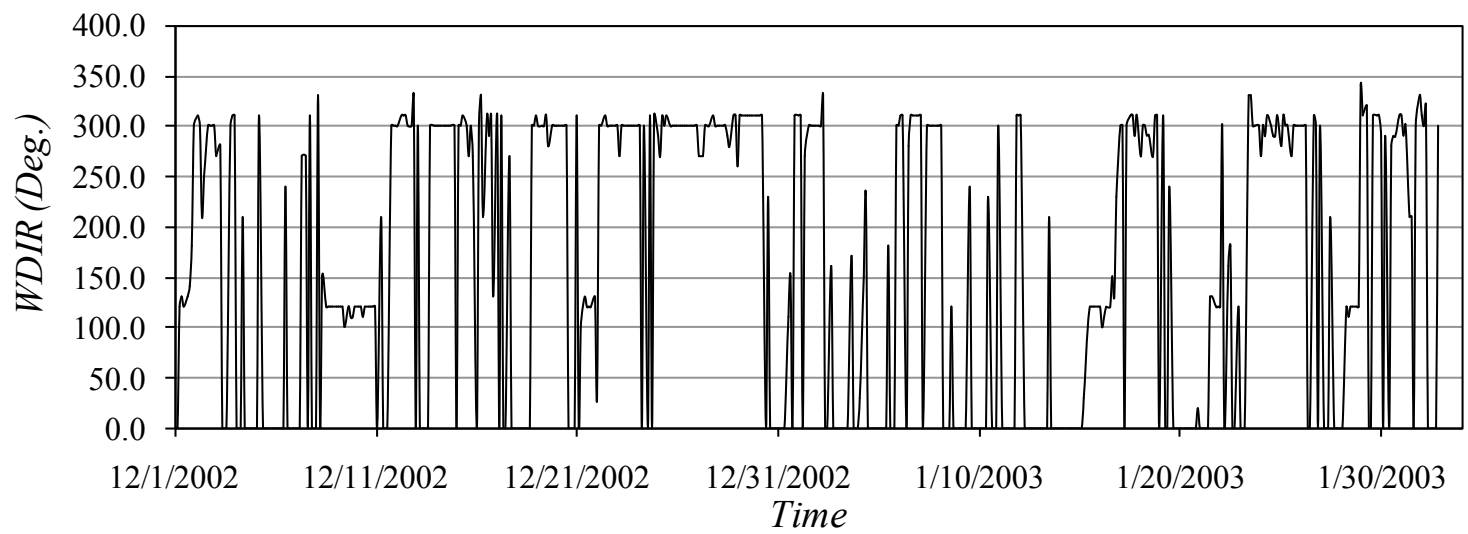

(c)

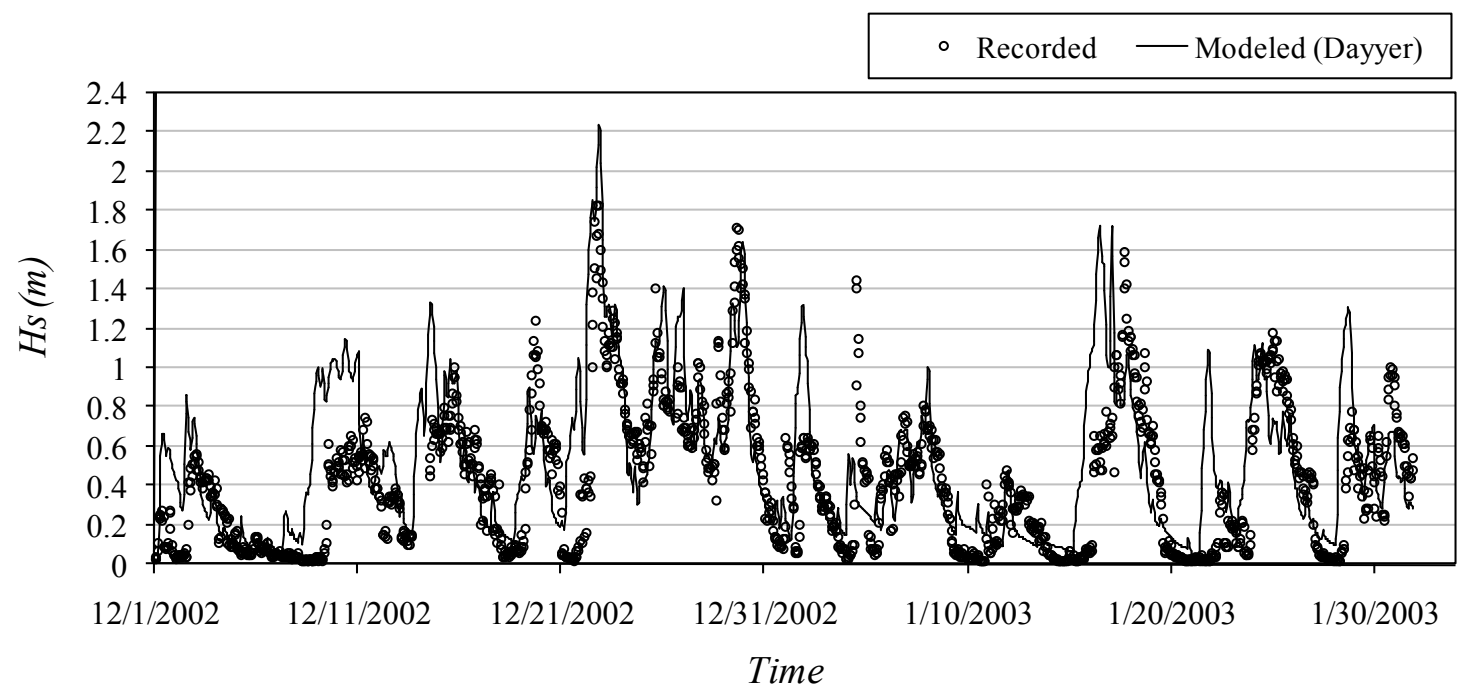

Fig. 3. Time series of wind and wave data in verification period with Dayyer wind forcing (a) Dayyer wind speed (b) Dayyer wind direction (c) Qualitative comparison of SWAN simulated (solid line) and measured (dots) Significant wave height. 
(a)

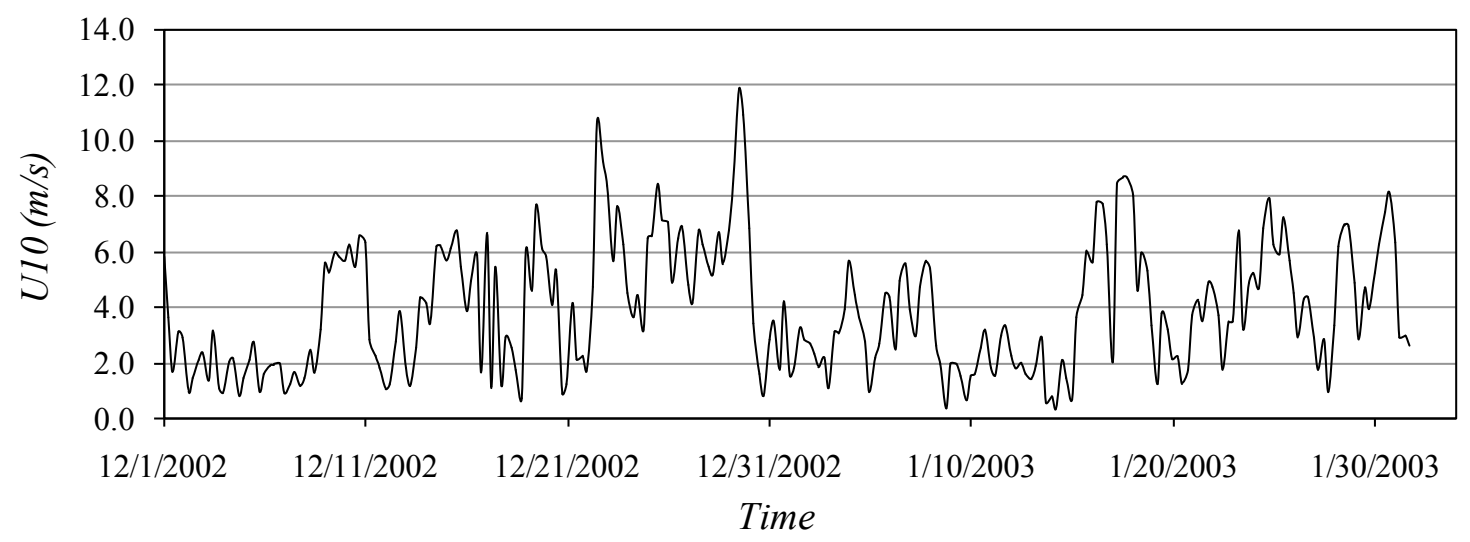

(b)

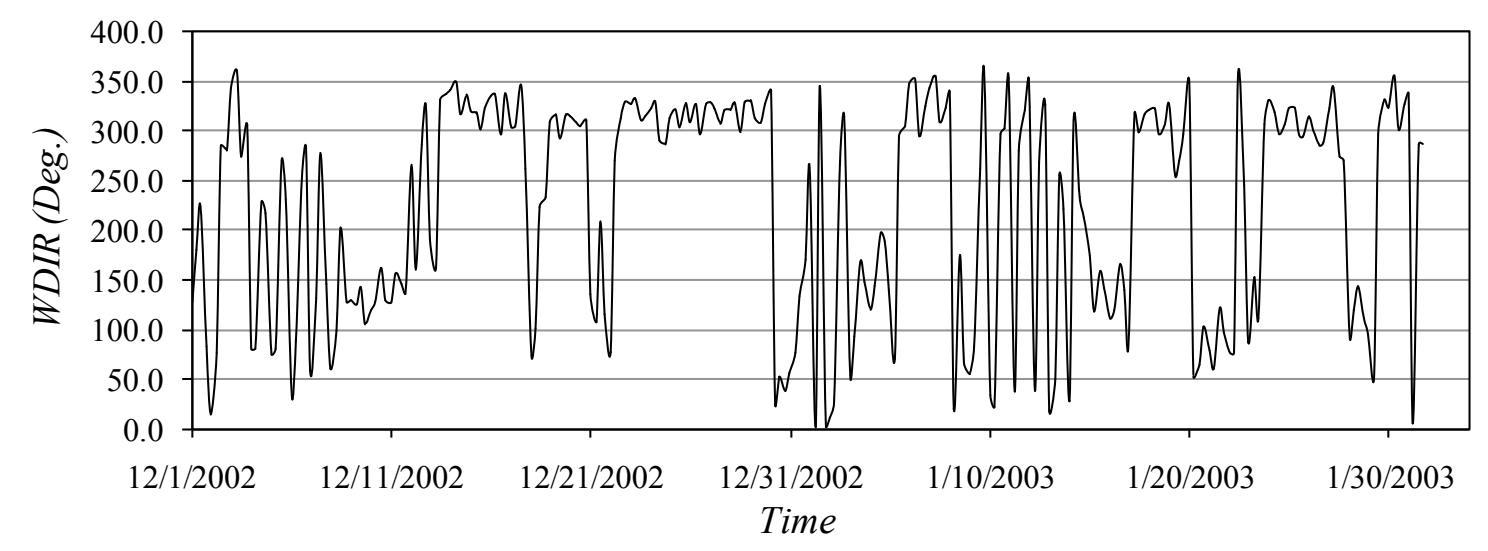

(c)

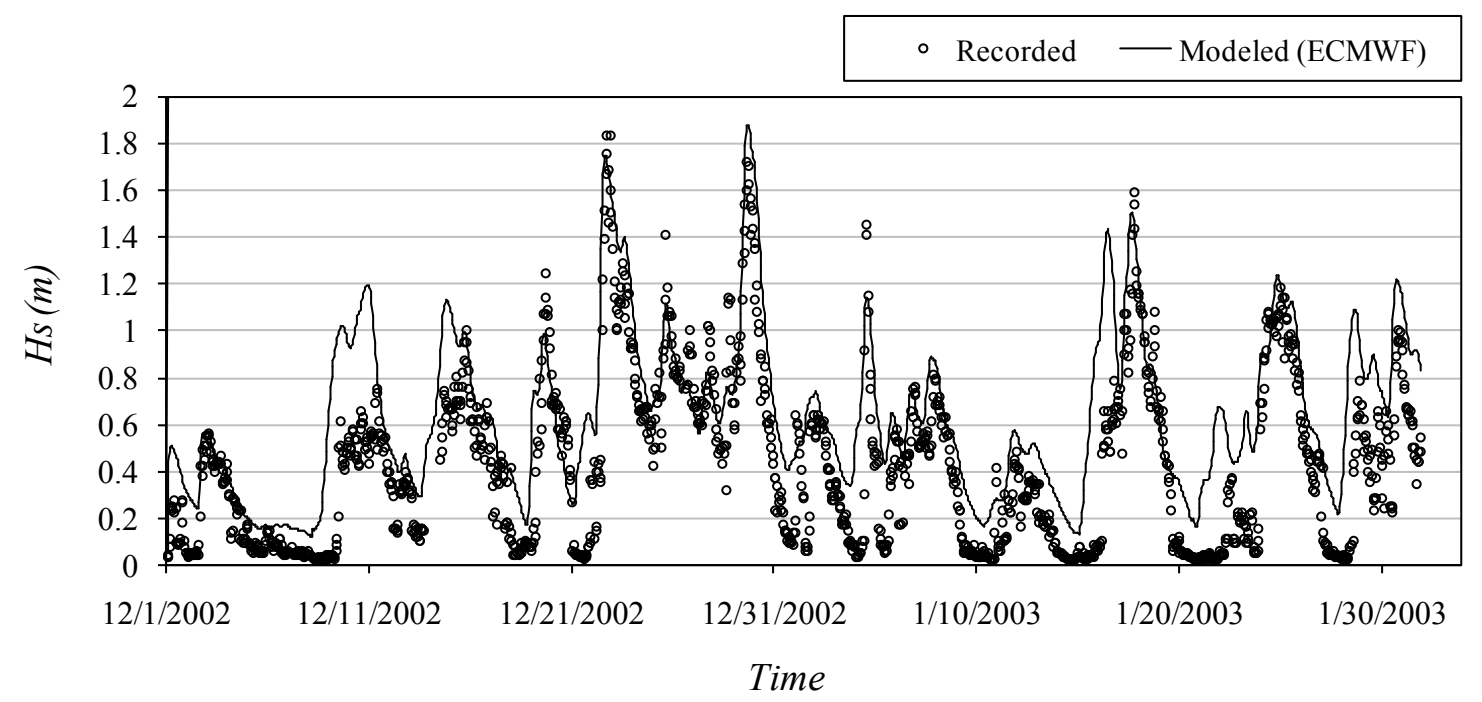

Fig. 4. Time series of wind and wave data in verification period with ECMWF wind forcing (a) ECMWF wind speed (b) ECMWF wind direction at the wave measurement location(c) Qualitative comparison of SWAN simulated (solid line) and measured (dots) Significant wave height. 
(a)

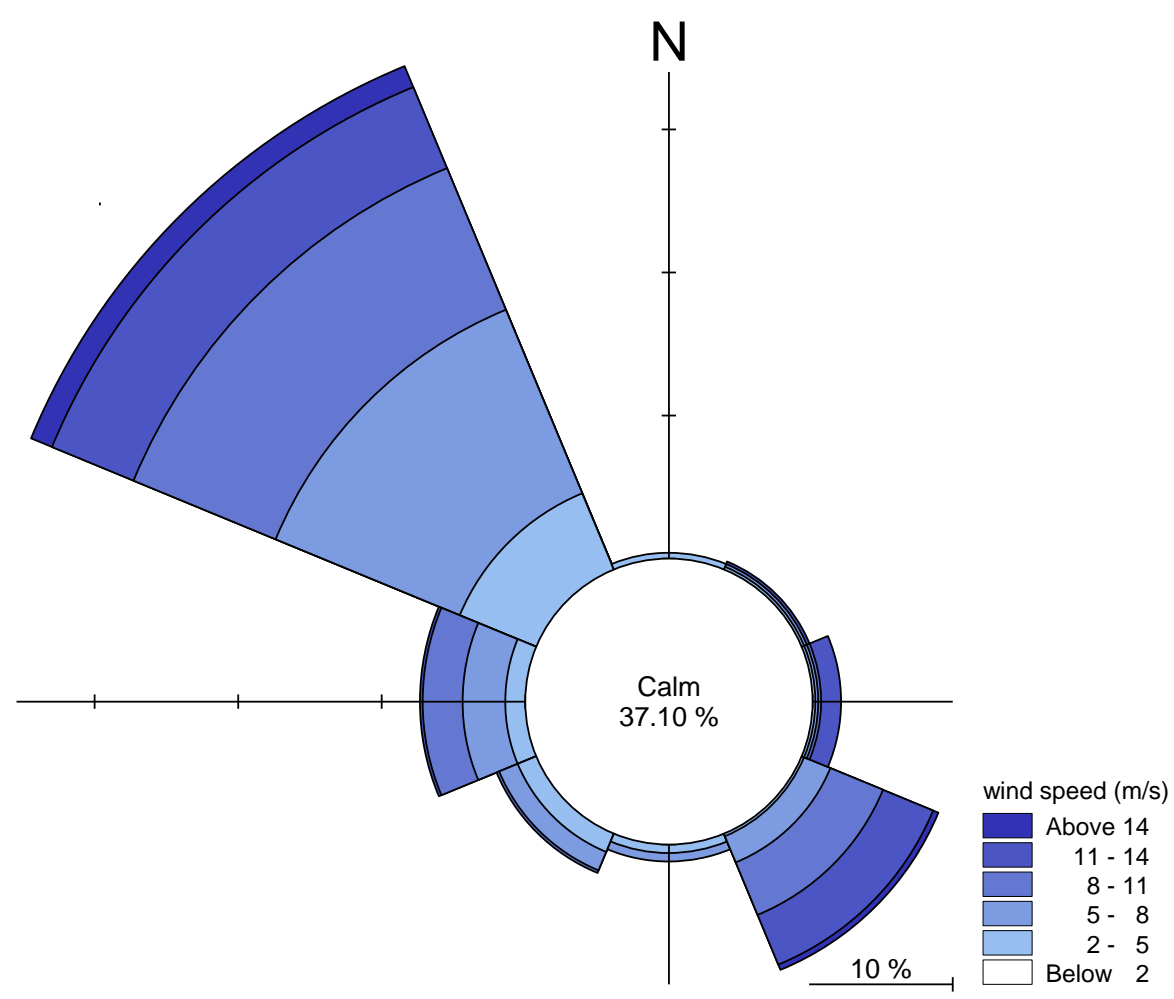

(b)

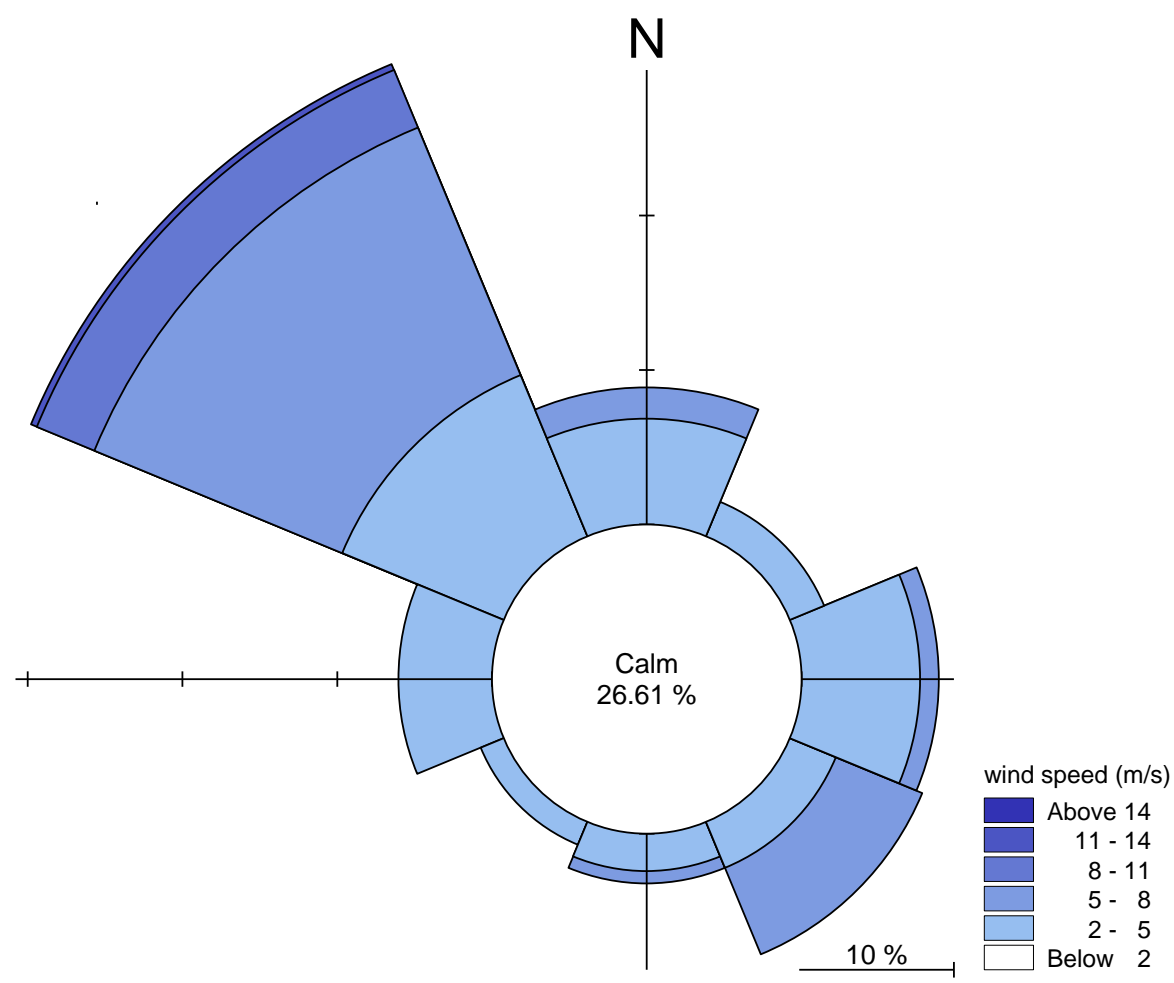

Fig. 5. (a) Dayyer and (b) ECMWF wind roses in verification period. 
(a)

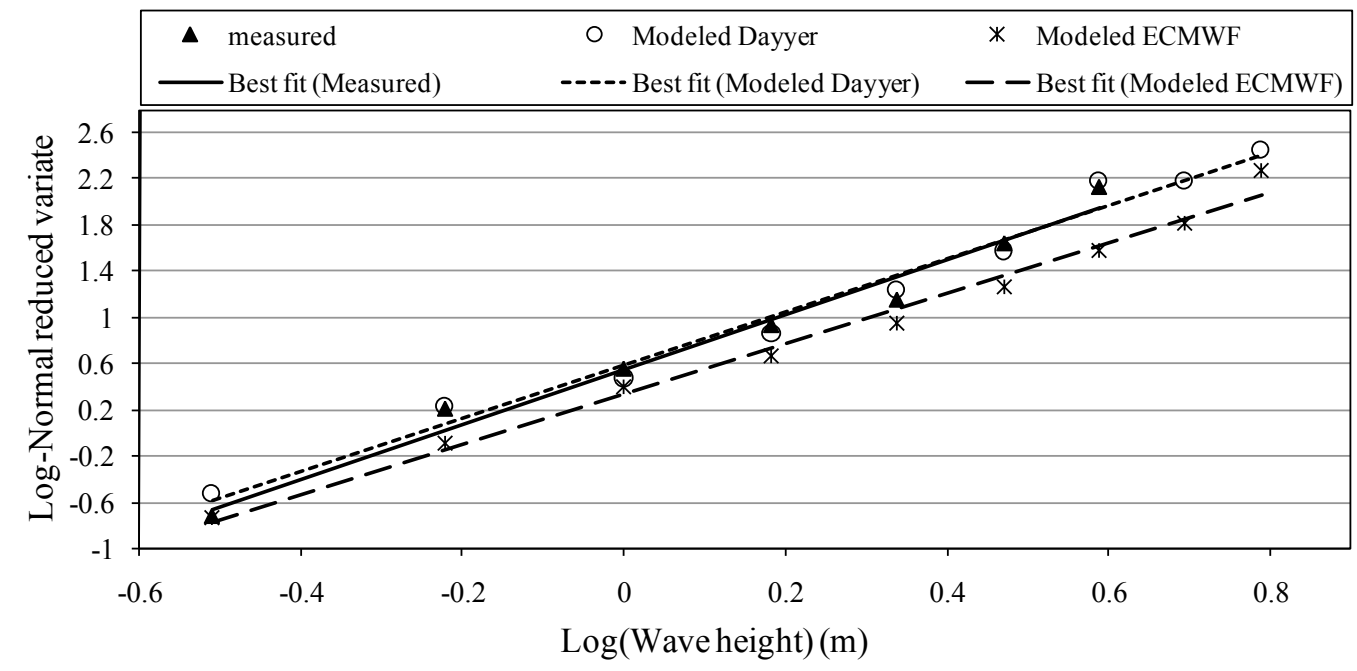

(b)

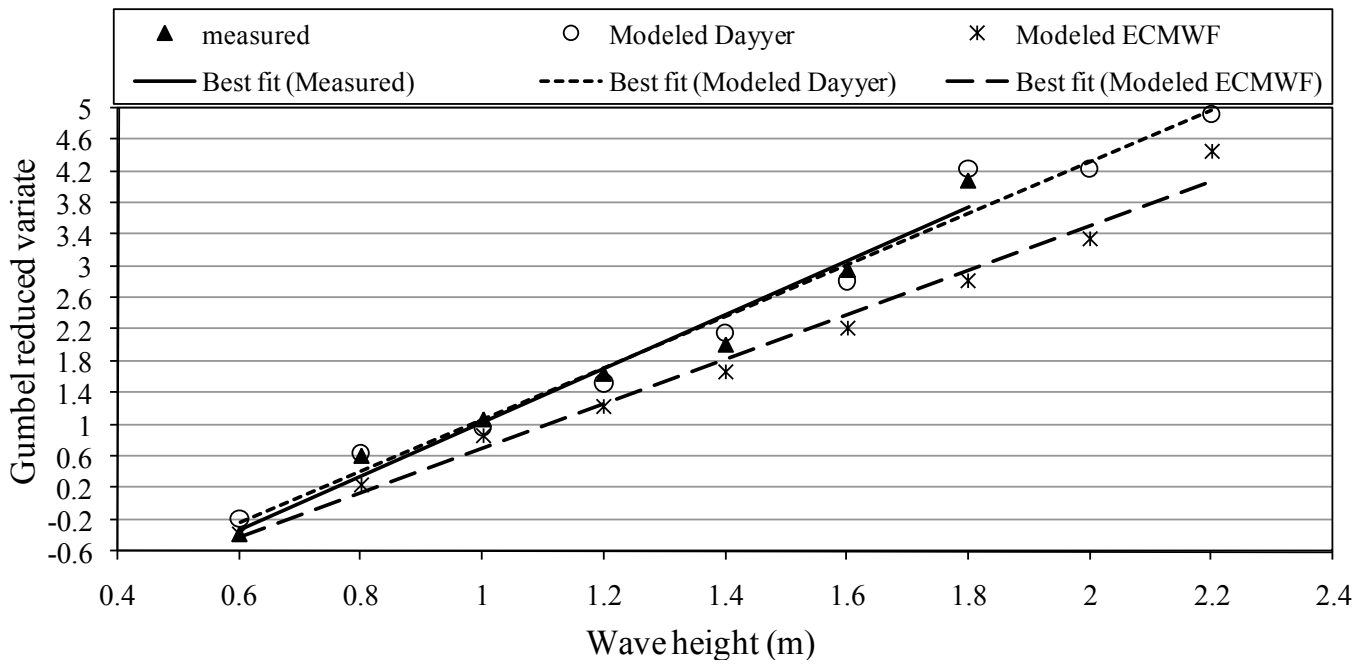

(c)

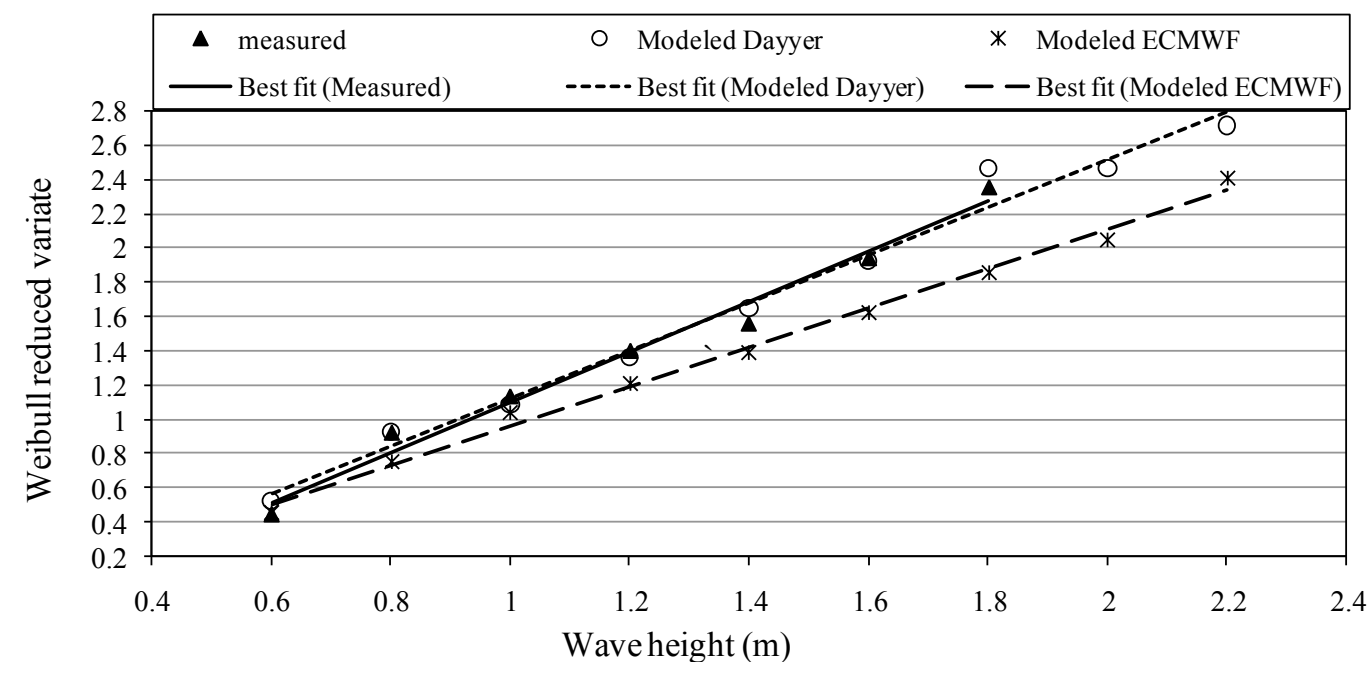

Fig. 6. (a) Log-Normal (b) Gumbel and (c) Weibull distribution plots for measured and modeled data. 


\section{Table's Caption:}

Table 1. Statistics of Dayyer and ECMWF wind data in calibration and verification period

Table 2. Distribution of SWAN modeled significant wave heights forced by Dayyer measurements versus recorded data (numbers are records in each category in percent of total, and a bold font represents maximum probability for each category)

Table 3. Distribution of SWAN modeled significant wave heights forced by ECMWF wind data versus measured data (numbers are records in each category in percent of total, and a bold font represents maximum probability for each category)

Table 4. Correlation coefficients between reduced variates of selected distributions and significant wave height for measured and modeled data

Table 5. The fitted Weibull distribution parameters for measured and modeled data for the threshold value of $0.5 \mathrm{~m}$.

Table 6. The return values of wave height for measured and simulated data predicted by the Weibull distribution and the threshold value of 0.5 meter

Table 7. Same as Table 6 but for threshold value of 1 meter 
Table 1. Statistics of Dayyer and ECMWF wind data in calibration and verification period

\begin{tabular}{cccc}
\hline & & Dayyer wind data & ECMWF wind data \\
\hline \multirow{3}{*}{$\begin{array}{c}\text { Calibration } \\
\text { Period }\end{array}$} & maximum $(\mathbf{m} / \mathbf{s})$ & 14.16 & 9.44 \\
\cline { 2 - 4 } & minimum $(\mathbf{m} / \mathbf{s})$ & 0.00 & 1.23 \\
\cline { 2 - 4 } & average $(\mathbf{m} / \mathbf{s})$ & 7.61 & 5.34 \\
\cline { 2 - 4 } & standard deviation $(\mathbf{m} / \mathbf{s})$ & 3.63 & 1.94 \\
\cline { 2 - 4 } Verification & maximum $(\mathbf{m} / \mathbf{s})$ & 17.85 & 11.86 \\
\cline { 2 - 4 } Period & minimum $(\mathbf{m} / \mathbf{s})$ & 0.00 & 0.79 \\
\cline { 2 - 4 } & average $(\mathbf{m} / \mathbf{s})$ & 7.59 & 5.32 \\
\cline { 2 - 4 } & standard deviation $(\mathbf{m} / \mathbf{s})$ & 3.90 & 2.13 \\
\hline
\end{tabular}


Table 2. Distribution of SWAN modeled significant wave heights forced by Dayyer measurements versus recorded data (numbers are records in each category in percent of total, and a bold font represents maximum probability for each category)

\begin{tabular}{ccccccc}
\hline Modeled (\%) & 75.04 & 20.01 & 4.42 & 0.53 & 0.00 & 100.00 \\
\hline $\mathbf{2 - 2 . 5}$ & 0.00 & 0.00 & 0.00 & 0.08 & 0.00 & 0.08 \\
\hline $\mathbf{1 . 5 - 2}$ & 0.27 & 0.32 & 0.33 & $\mathbf{0 . 1 8}$ & 0.00 & 1.10 \\
\hline $\mathbf{1 - 1 . 5}$ & 2.28 & 4.92 & $\mathbf{2 . 5 8}$ & 0.18 & 0.00 & 9.97 \\
\hline $\mathbf{0 . 5 - 1}$ & 13.47 & $\mathbf{1 0 . 7 4}$ & 1.33 & 0.08 & 0.00 & 25.63 \\
\hline $\mathbf{0 . 0 - 0 . 5}$ & $\mathbf{5 9 . 0 2}$ & 4.03 & 0.17 & 0.00 & 0.00 & 63.22 \\
\hline $\boldsymbol{H}_{\boldsymbol{S}}(\mathbf{m})$ & $\mathbf{0 . 0 - 0 . 5}$ & $\mathbf{0 . 5 - 1}$ & $\mathbf{1 - 1 . 5}$ & $\mathbf{1 . 5 - 2}$ & $\mathbf{2 - 2 . 5}$ & Measured (\%) \\
\hline
\end{tabular}


Table 3. Distribution of SWAN modeled significant wave heights forced by ECMWF wind data versus measured data (numbers are records in each category in percent of total, and a bold font represents maximum probability for each category)

\begin{tabular}{ccccccc}
\hline Modeled (\%) & 75.04 & 20.01 & 4.42 & 0.53 & 0.00 & 100.00 \\
\hline $\mathbf{2 - 2 . 5}$ & 0.07 & 0.07 & 0.15 & 0.08 & 0.00 & 0.37 \\
\hline $\mathbf{1 . 5 - 2}$ & 0.43 & 0.93 & 1.12 & $\mathbf{0 . 3 3}$ & 0.00 & 2.82 \\
\hline $\mathbf{1 - 1 . 5}$ & 3.83 & 6.74 & $\mathbf{2 . 5 2}$ & 0.12 & 0.00 & 13.20 \\
\hline $\mathbf{0 . 5 - 1}$ & 27.93 & $\mathbf{1 1 . 8 7}$ & 0.63 & 0.00 & 0.00 & 40.43 \\
\hline $\mathbf{0 . 0 - 0 . 5}$ & $\mathbf{4 2 . 7 8}$ & 0.40 & 0.00 & 0.00 & 0.00 & 43.18 \\
\hline $\boldsymbol{H}_{\boldsymbol{s}}(\mathbf{m})$ & $\mathbf{0 . 0 - 0 . 5}$ & $\mathbf{0 . 5 - 1}$ & $\mathbf{1 - 1 . 5}$ & $\mathbf{1 . 5 - 2}$ & $\mathbf{2 - 2 . 5}$ & Measured (\%) \\
\hline
\end{tabular}


Table 4. Correlation coefficients between reduced variates of selected distributions and significant wave height for measured and modeled data

\begin{tabular}{cccc}
\hline Distribution & $\begin{array}{c}\text { Measured } \\
\text { data }\end{array}$ & $\begin{array}{c}\text { Modeled data with } \\
\text { Dayyer wind }\end{array}$ & $\begin{array}{c}\text { Modeled data with } \\
\text { ECMWF wind }\end{array}$ \\
\hline Log-Normal & 0.9784 & 0.9821 & 0.9879 \\
\hline Gumbel & 0.9742 & 0.9807 & 0.9850 \\
\hline Weibull & $\mathbf{0 . 9 8 2 5}$ & $\mathbf{0 . 9 8 4 0}$ & $\mathbf{0 . 9 9 3 4}$ \\
\hline
\end{tabular}


Table 5. The fitted Weibull distribution parameters for measured and modeled data for the threshold value of $0.5 \mathrm{~m}$.

\begin{tabular}{cccc}
\hline $\begin{array}{c}\text { Weibull distribution } \\
\text { parameter }\end{array}$ & $\begin{array}{c}\text { Measured } \\
\text { data }\end{array}$ & $\begin{array}{c}\text { Modeled data with } \\
\text { Dayyer wind }\end{array}$ & $\begin{array}{c}\text { Modeled data with } \\
\text { ECMWF wind }\end{array}$ \\
\hline Shape parameter & 1.65 & 1.60 & 1.70 \\
\hline Scale parameter $(\mathrm{m})$ & 0.69 & 0.72 & 0.87 \\
\hline Location parameter $(\mathrm{m})$ & 0.24 & 0.19 & 0.16 \\
\hline
\end{tabular}


Table 6 . The return values of wave height for measured and simulated data predicted by the Weibull distribution and the threshold value of 0.5 meter

\begin{tabular}{cccccc}
\hline \multirow{2}{*}{ H $_{\mathbf{s}}$ extreme } & \multicolumn{5}{c}{ Return period (Year) } \\
\cline { 2 - 6 } & $\mathbf{2}$ & $\mathbf{5}$ & $\mathbf{1 0}$ & $\mathbf{2 0}$ & $\mathbf{5 0}$ \\
\hline Measured $(\mathbf{m})$ & 2.17 & 2.35 & 2.49 & 2.66 & 2.79 \\
\hline Modeled Dayyer $(\mathbf{m})$ & 2.31 & 2.52 & 2.67 & 2.86 & 3.00 \\
\hline Relative Error Dayyer $(\boldsymbol{\%})$ & 6.59 & 6.94 & 7.18 & 7.47 & 7.67 \\
\hline Modeled ECMWF $(\mathbf{m})$ & 2.45 & 2.68 & 2.85 & 3.06 & 3.21 \\
\hline Relative Error ECMWF $(\boldsymbol{\%})$ & 13.24 & 13.99 & 14.42 & 14.87 & 15.15 \\
\hline
\end{tabular}


Table 7. Same as Table 6 but for threshold value of 1 meter

\begin{tabular}{cccccc}
\hline \multirow{2}{*}{ H $_{\mathbf{s}}$ extreme } & \multicolumn{5}{c}{ Return period (Year) } \\
\cline { 2 - 6 } & $\mathbf{2}$ & $\mathbf{5}$ & $\mathbf{1 0}$ & $\mathbf{2 0}$ & $\mathbf{5 0}$ \\
\hline Measured $(\mathbf{m})$ & 2.04 & 2.16 & 2.25 & 2.36 & 2.44 \\
\hline Modeled Dayyer $(\mathbf{m})$ & 2.31 & 2.51 & 2.65 & 2.85 & 2.99 \\
\hline Relative Error Dayyer $(\boldsymbol{\%})$ & 13.32 & 15.87 & 17.87 & 20.59 & 22.69 \\
\hline Modeled ECMWF $(\mathbf{m})$ & 2.39 & 2.60 & 2.75 & 2.96 & 3.11 \\
\hline Relative Error ECMWF $(\boldsymbol{\%})$ & 17.04 & 20.09 & 22.33 & 25.21 & 27.32 \\
\hline
\end{tabular}

